\title{
Using External Prestressing to Enhance the Safety Performance of Existing Public Buildings
}

\author{
Jianmin ZHOU \\ Department of Architecture and Civil Engineering \\ Tongji University \\ Shanghai, China \\ e-mail: tjzhou2008@163.com \\ Pengfei QIN \\ Department of Architecture and Civil Engineering \\ Tongji University \\ Shanghai, China \\ e-mail: 1432116@tongji.edu.cn
}

\author{
Yifei WANG \\ Department of Architecture and Civil Engineering \\ Tongji University \\ Shanghai, China \\ e-mail: 1432117@tongji.edu.cn \\ Deqing QI \\ Department of Architecture and Civil Engineering \\ Tongji University \\ Shanghai, China \\ e-mail: deqingqi@tongji.edu.cn
}

\begin{abstract}
To use external prestressing to enhance the existing public buildings suffering from loss of reliability, this paper represents the static tests on 14 low strength concrete beams reinforced by external pre-stressed, and demonstrates an experiment on the mechanical performance of model beam, such as flexural bearing capacity of normal side, rigidity and crack. The result of experimental study shows that it is feasible and significant to spread the application of external prestressing to enhance the reliability of existing public buildings.
\end{abstract}

Keywords-low strength concrete; external pre-stressing; static test; reliability

\section{INTRODUCTION}

In China, a considerable amount of existing buildings have been suffering from loss of reliability, because of natural disasters or the change of their own environment, and they need to be strengthened. External pre-stressing is one of the strengthening techniques, which can improve the stiffness of the structure, so as to improve the reliability of structure.

Tongji University conducted the experiment on 14 low strength concrete beams with two kinds structure to prove that using external prestressing to enhance the reliability of existing public buildings is a good method.

\section{Specimen Design AND Test Method}

The test was conducted with placing a distributing girder on the span in the middle of the test beam, and applying concentrated force to the distributing girder by using loading device in order to load the test beam at two points. There are two kinds of span in the continuous beam, which is $4.2 \mathrm{~m}$ and $2.8 \mathrm{~m}$ respectively. The long span was loaded at the point of $1 / 3$, and the short one was loaded in the middle.

And a resistance strain gauge was pasted in the middle of longitudinal bar's specimen to measure the variation of reinforcement stresses during loading; along with a displacement meter putting at the side of beam span to measure the strain distributing law of concrete in the side beam surface along the height of section, so that to obtain the average curvature in the beam span. Furthermore, a displacement meters were placed in the support and pure bending in the middle span separately to measure the deflection in both two ends and the middle of the span.

The crack examination was conducted by painting the two sides of span with whitewash before experiment, and drawn a $50 \times 50 \mathrm{~mm}$ grid. During requirement experiment, crack could be discovered with naked eyes by using magnifier. Later, after crack occurred, it enable to examine the progress for crack immediately using the tool like electric crack measurement to measure the width of crack under different loading levels until the steel strain exceeds $1800 \mu \varepsilon$ that is the time to stop.

TABLE I. ACTUAL SitUATION OF SPECIMEN

\begin{tabular}{|l|l|l|l|l|l|l|l|l|}
\hline $\begin{array}{c}\text { Specimen } \\
\text { No. }\end{array}$ & $f_{\mathrm{cu}}$ & $\begin{array}{c}b \times h \times L \\
(\mathrm{~mm})\end{array}$ & $\begin{array}{c}\text { Pre-stressed } \\
\text { Reinforcement }\end{array}$ & $\begin{array}{c}\text { Longitudinal } \\
\text { Tensile } \\
\text { Reinforcement } \\
(1)\end{array}$ & $\begin{array}{c}\text { Erection } \\
b a r(2)\end{array}$ & Stimp(3) & $\begin{array}{c}\text { Reinforce } \\
\text { ment } \\
\text { Ratiop(\%) }\end{array}$ & $\begin{array}{c}\text { Tension } \\
\text { control of } \\
\text { effective } \\
\text { stress }\end{array}$ \\
\hline $\mathrm{L} 1-1$ & 31.44 & $250 \times 500 \times 4800$ & $2 \mathrm{As} 15.2$ & $2 \Phi 20$ & $2 \Phi 16$ & $\Phi 12 @ 80 / 200$ & 0.50 & $0.65 f_{\mathrm{ptk}}$ \\
\hline $\mathrm{L} 1-2$ & 40.07 & $250 \times 500 \times 4800$ & $2 \mathrm{As} 15.2$ & $2 \Phi 20$ & $2 \Phi 16$ & $\Phi 12 @ 80 / 200$ & 0.50 & $0.55 f_{\mathrm{ptk}}$ \\
\hline
\end{tabular}


TABLE i. Actual Situation of Specimen (Cont.)

\begin{tabular}{|c|c|c|c|c|c|c|c|c|}
\hline $\begin{array}{l}\text { Specimen } \\
\text { No. }\end{array}$ & $f_{\mathrm{cu}}$ & $\begin{array}{c}b \times h \times L \\
(m m)\end{array}$ & $\begin{array}{c}\text { Pre-stressed } \\
\text { Reinforcement }\end{array}$ & $\begin{array}{l}\text { Longitudinal } \\
\text { Iensile } \\
\text { Reinforcement } \\
\text { (1) }\end{array}$ & $\begin{array}{c}\text { Erection } \\
\text { bar(2) }\end{array}$ & Stirnup(3) & $\begin{array}{c}\text { Reinforce } \\
\text { ment } \\
\text { Ratiop(\%) }\end{array}$ & $\begin{array}{l}\text { Tension } \\
\text { control of } \\
\text { effective } \\
\text { stress } \\
\end{array}$ \\
\hline L2-1 & 31.44 & $250 \times 500 \times 4800$ & 2 As 15.2 & $3 \Phi 20$ & $2 \Phi 16$ & $\Phi 12 @ 80 / 200$ & 0.75 & $0.53 f_{\mathrm{pts}}$ \\
\hline L2-2 & 40.07 & $250 \times 500 \times 4800$ & 2As15.2 & $3 \Phi 20$ & $2 \Phi 16$ & $\Phi 12 @ 80 / 200$ & 0.75 & $0.52 f_{\text {pos }}$ \\
\hline L3-1 & 31.44 & $250 \times 500 \times 4800$ & 2 As 15.2 & $2 \Phi 20$ & $2 \Phi 16$ & $\Phi 12 @ 80 / 200$ & 0.50 & $0.43 f_{\mathrm{pt}}$ \\
\hline L3-2 & 40.07 & $250 \times 500 \times 4800$ & 2 As 15.2 & $3 \Phi 20$ & $2 \Phi 16$ & $\Phi 12 @ 80 / 200$ & 0.75 & $0.43 f_{\mathrm{pts}}$ \\
\hline B1-1 & 16.04 & $250 \times 450 \times 4500$ & 2 As 15.2 & $3 \Phi 25$ & $2 \Phi 16$ & $\Phi 12 @ 80 / 200$ & 1.31 & $0.45 f_{\mathrm{pk}}$ \\
\hline B1-2 & 35.32 & $250 \times 450 \times 4500$ & 2As15.2 & $3 \Phi 25$ & $2 \Phi 16$ & $\Phi 12 @ 80 / 200$ & 1.31 & $0.48 f_{\mathrm{ptk}}$ \\
\hline B2-1 & 16.04 & $250 \times 450 \times 4500$ & $2 \mathrm{As} 15.2$ & $2 \Phi 25$ & $2 \Phi 20$ & $\Phi 12 @ 80 / 200$ & 0.87 & $0.51 f_{\mathrm{ptk}}$ \\
\hline B2-2 & 35.32 & $250 \times 450 \times 4500$ & 2 As 15.2 & $2 \Phi 25$ & $2 \Phi 20$ & $\Phi 12 @ 80 / 200$ & 0.87 & $0.45 f_{\mathrm{pk}}$ \\
\hline T3-1 & 16.04 & $250 \times 450 \times 4500$ & 2 As 15.2 & $3 \Phi 25$ & $2 \Phi 16$ & $\$ 12 @ 80 / 200$ & 1.08 & $0.49 f_{\mathrm{ps}}$ \\
\hline T3-2 & 35.32 & $250 \times 450 \times 4500$ & 2 As 15.2 & $3 \Phi 25$ & $2 \Phi 16$ & $\Phi 12 @ 80 / 200$ & 1.08 & $0.48 f_{\mathrm{pk}}$ \\
\hline B4-1 & 16.04 & $250 \times 400 \times 7000$ & 2 As 15.2 & $2 \Phi 20$ & $2 \Phi 16$ & $\Phi 12 @ 80 / 200$ & 0.63 & $0.41 f_{\mathrm{pkk}}$ \\
\hline B4-2 & 35.32 & $250 \times 400 \times 7000$ & 2 As 15.2 & $2 \Phi 20$ & $2 \Phi 16$ & $\Phi 12 @ 80 / 200$ & 0.63 & $0.48 f_{\mathrm{ptk}}$ \\
\hline
\end{tabular}

Beam T3-1, T3-2 is T-section; average width of compressed flange is 550mm; height of compressed flange is 80mm; Usually dispose П- Stirrup $8 @ 200$ and construction longitudinal bar 216 in flange

\section{EXPERIMENT PROCEDURES AND PHENOMENAG}

\section{A. Experiment Procedures and Phenomena for} Rectangular Simply-supported Beam

There are 10 rectangular simply supported beams, and their loading procedures are similar. Because of different concrete strength and reinforcement, their experiment phenomena are roughly analogous without significant difference. Fig.1 shows the load-deflection curve of rectangular simply-supported test beam L2-1.

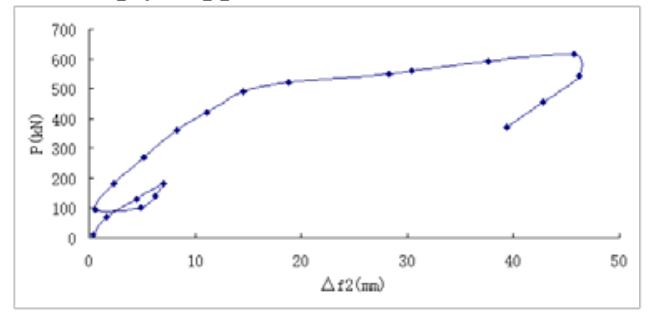

Figure 1. Load deflection curve for Test beam L2-1

\section{B. Experiment procedure and phenomena for simply supported T-beams}

There are two simply supported T-beams designed in this experiment, the loading system is same with the previous rectangular simply supported beam. However, the phenomenon was different. Fig.4 shows the load-deflection curve of the simply supported T-beam T3-2.

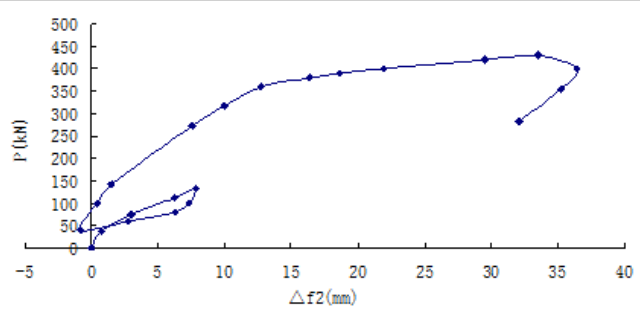

Figure 2. Load deflection curve for Test beam L3-2

\section{Experiment Procedure and Phenomenon for Continuous Beam}

After that, we also designed 2 continuous beams in this experiment. By loading the short span and the long span simultaneously, even the loading principle was the same with the simply supported beam, but the phenomenon varied significantly. Fig.3 and Fig.4 display the load-deflection curve for the long span and the short span of rectangular continuous beamB4-1.

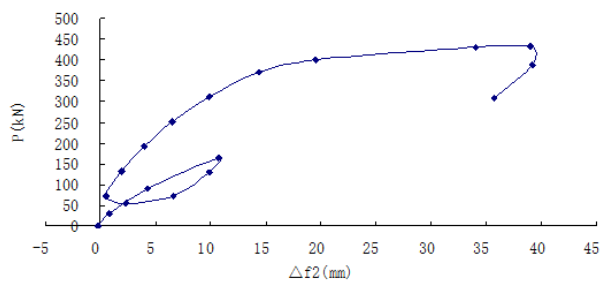

Figure 3. Load-deflection curve for test beamB4-1 (long span)

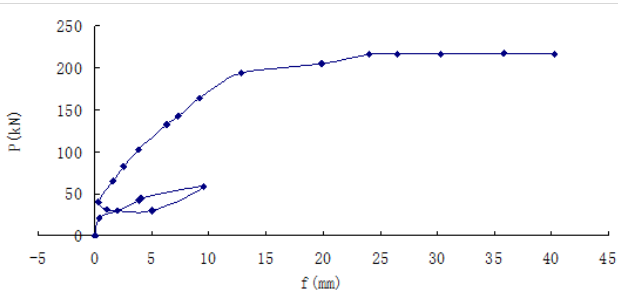

Figure 4. Load-deflection curve for test beamB4-1(short span)

\section{ANALYSIS OF EXPERIMENT RESULT}

As was stated above, the following factors have been considered for the beam testing: concrete strength, section types (rectangle and T-shaped), non-pre-stressed 
reinforcement ratio and loading system. The impact is mainly on the aspects such as bearing capacity, rigidity, and deflection, crack and so on. When grouped comparing the impactions of these factors, one factor can be treated as variable, while the others being constant.

\section{A. Effect of Concrete Strength}

Define abbreviations and acronyms the first time they are used in the text, even after they have been defined in the abstract. Do not use abbreviations in the title or heads unless they are unavoidable.

There are 4 levels of concrete strength for the beam testing, whose standard value for the cube compressive strength is $16.04 \mathrm{MPa}, 31.44 \mathrm{MPa}, 35.32 \mathrm{MPa}$ and $40.07 \mathrm{MPa}$ respectively. Through the comparison for 6 groups of beam (L1-1 VS L1-2, L2-1 VS L2-2, B1-1 VS B1-2, B2-1 VS B2-
2, T3-1 VS T3-2 and B4-1 VS B4-2), it can reflect that the variation of concrete strength has influence on the flexural property listing in Table 2-3for details.

From the application of external pre-stressing on the low strength concrete beam, the lowest compressive strength for the testing beam's concrete axis is 16.04MPa. After strengthening with external pre-stressing, the flexural property can be improved, especially on the bearing capacity. From the comparisons from Group 3 to Group 6 shown, the difference of bearing capacity between the low strong concrete beam (strengthened by external pre-stressing) and $35 \mathrm{MPa}$ concrete beam is around $10 \%$. Hence, the external pre-stressing method can be used to strength a low strong concrete beam with an evident strengthening effect.

TABLE II. FleXural Property of TESt BeAm (StRENGTH)

\begin{tabular}{|c|c|c|c|c|c|c|c|c|c|}
\hline \multirow{2}{*}{ Flexural property } & \multicolumn{3}{|c|}{ Comparison for Group1 } & \multicolumn{3}{|c|}{ Comparison for Group2 } & \multicolumn{3}{|c|}{ Comparison for Group3 } \\
\hline & L1-1 & $L 1-2$ & Ratio & $L 2-1$ & $L 2-2$ & Ratio & B1-1 & B1-2 & Ratio \\
\hline$f_{c{ }_{(\mathrm{MPa})}}$ & 31.44 & 40.07 & 1.27 & 31.44 & 40.07 & 1.27 & 16.04 & 35.32 & 2.20 \\
\hline$A_{\mathrm{s}}\left(\mathrm{mm}^{2}\right)$ & 628 & 628 & 1.00 & 942 & 942 & 1.00 & 1472 & 1472 & 1.00 \\
\hline$P_{{ }_{(\mathrm{kN})}}$ & 437 & 400 & 0.92 & 432 & 476 & 1.10 & 425 & 579 & 1.36 \\
\hline Deflection f(mm) & 27.25 & 48.84 & 1.79 & 33.54 & 23.40 & 0.70 & 13.94 & 21.20 & 1.52 \\
\hline$B_{s}^{T}\left(10^{3} \mathrm{kN} \cdot \mathrm{m}\right)$ & 10.28 & 6.96 & 0.68 & 9.84 & 8.19 & 0.83 & 50.92 & 45.48 & 0.89 \\
\hline$\omega_{\max }^{T}(\mathrm{~mm})$ & 0.18 & 0.36 & 2.00 & 0.32 & 0.30 & 0.94 & 0.22 & 0.18 & 0.82 \\
\hline
\end{tabular}

TABLE III. FleXURAl PRoPerty OF TEST BeAm (STRENGTH)

\begin{tabular}{|c|c|c|c|c|c|c|c|c|c|}
\hline \multirow{2}{*}{ Flexural property } & \multicolumn{3}{|c|}{ Comparison for Group4 } & \multicolumn{3}{|c|}{ Comparison for Group5 } & \multicolumn{3}{|c|}{ Comparison for Group6 } \\
\hline & B2-1 & B2-2 & Ratio & T3-1 & T3-2 & Ratio & B4-1 & B4-2 & Ratio \\
\hline$f_{c u(\mathrm{MPa})}$ & 16.04 & 35.32 & 2.20 & 16.04 & 35.32 & 2.20 & 16.04 & 35.32 & 2.20 \\
\hline$A_{\mathrm{s}}\left(\mathrm{mm}^{2}\right)$ & 981 & 981 & 1.00 & 1472 & 1472 & 1.00 & 628 & 628 & 1.00 \\
\hline$P_{u_{(\mathrm{kN})}}$ & 412 & 468 & 1.14 & 518 & 615 & 1.19 & 430 & 470 & 1.09 \\
\hline Deflection f(mm) & 14.45 & 26.59 & 1.84 & 15.92 & 30.44 & 1.91 & 15.20 & 17.80 & 1.17 \\
\hline$B_{s}^{T}\left(10^{3} \mathrm{kN} \cdot \mathrm{m}\right)$ & 34.33 & 17.58 & 0.51 & 95.35 & 21.90 & 0.23 & 47.37 & 29.24 & 0.62 \\
\hline$\omega_{\max }^{T}(\mathrm{~mm})$ & 0.26 & 0.31 & 1.19 & 0.19 & 0.26 & 1.37 & 0.22 & 0.24 & 1.09 \\
\hline
\end{tabular}

Notes: Comparing with data between short-term rigidity and short term crack width which is under $0.8 M_{\mathrm{u}}$ loading level, the third column is the ratio of the former one and the latter one. $A_{\mathrm{S}}$ is the Area of

$$
\text { non pre-stressed tensile reinforcement , } \mathrm{f} \text { is deflection in the middle of the span, } B_{s}^{T} \text { is the rigity, } \omega_{\max }^{T} \text { is maximum Crack width and } P_{u} \text { is bearing capacity. }
$$

\section{B. Effect for Section Types of Concrete Beam}

The impaction of section type mainly exists in the difference between T-shaped section and rectangular section, e.g. test beam B2-1 VS T3-1, B2-2 VS T3-2 showing in
Table 3 From the data demonstrated, the bearing capacity of T-shaped section is increased by $30 \%$ than rectangular section, as well as the short term rigidity is improved by $25 \%-178 \%$, even with the same reinforcement, concrete strength and section size. So the influence of T-shaped 
section strengthened by external pre-stressing is much better

than the one of rectangular section.

C. Effect for Non Pre-stressing Tensile Reinforcement Ratio

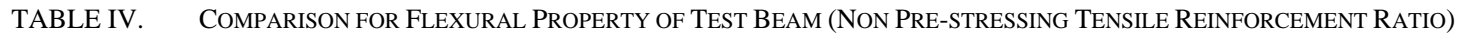

\begin{tabular}{|c|c|c|c|c|c|c|c|c|c|c|c|c|}
\hline \multirow{2}{*}{ Flexural property } & \multicolumn{3}{|c|}{ Comparison for Group7 } & \multicolumn{3}{|c|}{ Comparison for Group8 } & \multicolumn{3}{|c|}{ Comparison for Group9 } & \multicolumn{3}{|c|}{ Comparison for Group10 } \\
\hline & L1-1 & $L 2-1$ & Ratio & L1-2 & $L 2-2$ & Ratio & B1-1 & B2-1 & Ratio & B1-2 & $B 2-2$ & Ratio \\
\hline$f_{c{ }_{(\mathrm{MPa})}}$ & 31.44 & 34.44 & 40.10б0 & 40.07 & 40.00 & 1.00 & 16.04 & 16.04 & 1.00 & 35.32 & 35.32 & 1.00 \\
\hline$A_{s}\left(m m^{2}\right)$ & 628 & 942 & 1.5 & 628 & 942 & 1.5 & 1472 & 981 & 1.50 & 1472 & 981 & 1.50 \\
\hline$P_{u_{(\mathrm{kN})}}$ & 437 & 432 & 0.99 & 400 & 476 & 1.19 & 425 & 412 & 1.03 & 579 & 468 & 1.24 \\
\hline Deflection f(mm) & 27.25 & 33.54 & 1.23 & 48.84 & 23.4 & 0.48 & 13.94 & 14.45 & 0.96 & 21.20 & 26.59 & 0.80 \\
\hline$B_{s}^{T}\left(10^{3} \mathrm{kN} \cdot \mathrm{m}\right)$ & 102.79 & 98.14 & 0.95 & 69.61 & 81.92 & 1.18 & 50.92 & 34.33 & 1.48 & 45.48 & 17.58 & 2.59 \\
\hline$\omega_{\max }^{T}(\mathrm{~mm})$ & 0.18 & 0.32 & 1.78 & 0.36 & 0.30 & 0.86 & 0.22 & 0.26 & 0.85 & 0.18 & 0.31 & 0.58 \\
\hline
\end{tabular}

The outcome of the non pre-stressing tensile reinforcement ratio is mainly presented in the comparison of these 4 groups (L1-1 VS L2-1, L1-2 VS L2-2, B1-1 VS B2-1, B1-2 VS B2-2) in Table 4. From the experimental data shown in tables, when the section sizes are same, there are growths in the tensile reinforcement, the bearing capacity, the short-term rigidity and maximum width of crack with 50\%, 10\%-20\%, 20\%-150\% and 15\%-40\% respectively. So the increasing amount of non-pre-stressing reinforcement has great effect on the flexural property of external pre- stressing concrete beam.

\section{Some Effect of Loading System}

TABLE V. COMPARISON For FleXural PRoperty of TeSt BEAM (LOADING SYSTEM)

\begin{tabular}{|c|c|c|c|c|c|c|}
\hline \multirow{2}{*}{$\begin{array}{c}\text { Flexural } \\
\text { property }\end{array}$} & \multicolumn{3}{|c|}{$\begin{array}{c}\text { Comparison for } \\
\text { Group11 }\end{array}$} & \multicolumn{3}{c|}{$\begin{array}{c}\text { Comparison for } \\
\text { Group12 }\end{array}$} \\
\cline { 2 - 7 } & L1-1 & L3-1 & Ratio & L2-2 & L3-2 & Ratio \\
\hline $\mathrm{f}_{c u}(\mathrm{Mpa})$ & $\begin{array}{c}16.0 \\
4\end{array}$ & 16.04 & 1.00 & 35.32 & 35.32 & 1.00 \\
\hline$A_{\mathrm{s}}\left(\mathrm{mm}^{2}\right)$ & 1472 & 981 & 1.50 & 1472 & 981 & 1.50 \\
\hline $\mathrm{P}_{u}(\mathrm{kN})$ & 425 & 412 & 1.03 & 579 & 468 & 1.24 \\
\hline $\mathrm{f}(\mathrm{mm})$ & $\begin{array}{c}13.9 \\
4\end{array}$ & 14.45 & 0.96 & 21.20 & 26.59 & 0.80 \\
\hline $\mathrm{B}_{S}^{T}$ & $\begin{array}{c}50.9 \\
2\end{array}$ & 34.33 & 1.48 & 45.48 & 17.58 & 2.59 \\
\hline $\begin{array}{c}\text { sequence of } \\
\text { pre-stressed } \\
\text { concrete }\end{array}$ & Later & First & & Later & First & \\
\hline
\end{tabular}

There are two kinds of loading systems: one is the loadunload-pre-tensioned steel strand-load and the other is pretensioned steel strand - load. The effect of loading system is mainly on the comparison of testing beams (L1-1 VS L3-1 and L2-2 VS L3-2) in Table 5. From the date shown in the table, the difference of bearing capacity between these two loading systems is less than $10 \%$ under the same condition. Besides the tensioned control of effective stress causes low bearing capacity. Also test beams are close to each other in bearing capacity under these two loading systems, therefore two systems have little impact on the bearing capacity of test beams. However, the deflection of the latter loading system is larger by $50 \%-110 \%$ than the former one, thus two loading systems have too much effect on the deflection of test beam.

TABLE VI. COMPARISON FOR FLEXURAL PROPERTY OF TEST BEAM (STRUCTURE)

\begin{tabular}{|c|c|c|c|c|c|c|}
\hline \multirow{2}{*}{$\begin{array}{c}\text { Flexural } \\
\text { property }\end{array}$} & \multicolumn{3}{|c|}{$\begin{array}{c}\text { Comparison for } \\
\text { Group13 }\end{array}$} & \multicolumn{3}{c|}{$\begin{array}{c}\text { Comparison for } \\
\text { Group14 }\end{array}$} \\
\cline { 2 - 7 } & $\mathbf{B 1 - 1}$ & $\mathbf{B 4 - 1}$ & Ratio & B1-2 & B4-2 & Ratio \\
\hline $\mathrm{f}_{c u}(\mathrm{Mpa})$ & $\begin{array}{c}16.0 \\
4\end{array}$ & 16.04 & 1.00 & 35.32 & 35.32 & 1.00 \\
\hline$A_{\mathrm{s}}\left(\mathrm{mm}^{2}\right)$ & 1472 & 981 & 1.50 & 1472 & 981 & 1.50 \\
\hline $\mathrm{P}_{u}(\mathrm{kN})$ & 425 & 412 & 1.03 & 579 & 468 & 1.24 \\
\hline $\begin{array}{c}\text { Support } \\
\text { type }\end{array}$ & $\mathrm{s}$ & $\mathrm{c}$ & & $\mathrm{s}$ & $\mathrm{C}$ & \\
\hline
\end{tabular}

\section{E. Effect of Structure}

There are two kinds of structures: one is the simply supported beam and the other is the continuous beam. The testing results for comparison are B1-1 VS B4-1 and B1-2 VS B4-2 listed in Table 6. From the data shown in the table, after the external pre-tensioned stress reinforces the simply supported beam, its reinforcement ratio and size is larger than that of continuous beam, but with a 5\% less bearing capacity. As a result, the effect on continuous beam reinforced by the external pre-tensioned stress is better than the simply supported beam in the aspect of bearing capacity.

\section{CONCLUSION}

Based on the following experiments, it can come to the conclusion as below:

After low strength concrete beam is strengthened by the external pre-tensioned stress, its flexural properties (such as bearing capacity, rigidity, crack and so on) are improved dramatically. For example, bearing capacity is 2-3 times higher than before. So that it can resolve the problem caused by the insufficient bearing capacity, which cannot meet related requirements. Applying external pre-stressing can 
make component counter-vault, thus reducing the probability of deformation. In addition, it can also avoid the problem of excessive deformation, and make the concrete tensile region produce the pre-pressure so that increasing the cracking load for beams, postponing the appearance of cracks as well as improving the component's usability:

(1) Bearing capacity

Factors of the concrete rigidity, the non-pre-stressed tensile reinforcement ratio, section type and structure all have impacts on the effect of external pre-stressing; the section type has the most obvious impact. The bearing capacity for T-beam is $26 \%-31 \%$ higher than that for rectangular beam even under the same situation. Next comes to the effect of concrete strength, if the concrete strength is increased by $120 \%$, the bearing capacity will improve by $10 \%-20 \%$.

(2) Rigidity

For the rigidity of external pre-stressing concrete, both the section format and the non-pre-tensioned stress tensile reinforcement ratio are the major elements, and then is the concrete strength.

(3) Crack
As for crack, the concrete strength, the section type and the tensile reinforcement affect more, while the effect of structure impacts slightly.

As a result, it is effective to use the external pre-stressing technology to improve the the reliability of existing public buildings.

\section{ACKNOWLEDGEMENT}

The authors thank the Ministry of science and technology for supporting this work as part of National key research program.(2016YFC0700701).The authors also thank Tongji University for providing the experimental conditions.

\section{REFERENCES}

[1] Li Yanhe. (2008) Theory and Application of effective strengthing prestressed method, Science Press.

[2] Li Yanhe. and Chen Gui. (1998) Study on pretensioned stress strengthed method design Computing Method.Construction Quality Supervision, 1998, (2):21 29.

[3] Xiong Xueyu, Lei Liying and Gu Wei. (1998) Assessment of pretensioned stress loss for external pretensioned stress, structure industrial architecture, 2004, 34(7):16 19.

[4] Wang Hongju. (2010) Experimental study and analysis on concrete beam strengthed by external prestressing: Master Dissertation. Shanghai: Tongji University. 